\title{
Multiparametric Imaging Improves Confidence in the Diagnosis of Multinodular and Vacuolating Neuronal Tumor of the Cerebrum
}

W e read with much interest the article by Nunes et $\mathrm{al}^{1}$ in the July 2017 issue of the American Journal of Neuroradiology, in which they presented an impressive series of 33 confirmed or presumed multinodular and vacuolating neuronal tumors (MVNT) of the cerebrum, an entity that has only recently been categorized in the 2016 revision of the World Health Organization Classification of Tumors of the Central Nervous System. ${ }^{2-4}$ Only a few cases of MVNT have been reported in the literature in the past 4 years with confirmed pathologic correlations. ${ }^{1-3}$

The authors presented a detailed description of the entity, which involves the deep cortical ribbon and the adjacent subcortical white matter and is distributed into small coalescent nodules, hyperintense on FLAIR and T2-weighted imaging and hypointense on T1WI. On our 3T MR imaging, we noticed that these lesions were not homogeneous but had a central FLAIR hyposignal as well as central punctiform T1 hyperintensities (white arrows, Fig 1), probably related to a high protein or solid component within the vacuolated areas. This specific feature was present in all our patients but requires reasonably high resolution to be seen. This simple sign can improve diagnostic confidence.

We believe that radiologists should always perform multiparametric imaging to characterize brain abnormalities consistent with an MVNT with a high-field MR imaging whenever possible. In our experience, diffusion-weighted imaging shows no restricted diffusion inside the lesion, and susceptibilityweighted imaging does not show an intratumoral susceptibility signal or intralesional hemorrhaging. Perfusion sequences such as dynamic-susceptibility contrast or arterial spin-labeling show no hyperperfusion, increasing neither cerebral blood volume nor cerebral blood flow. MR spectroscopy may show a mild decrease of NAA but no choline peak or lipid or lactate peaks, which might suggest malignancy (Fig 2). Multivoxel MR spectroscopy shows no abnormality in the surrounding brain parenchyma. All these features improve diagnostic confidence and support strong arguments in favor of this presumptive diagnosis, thus avoiding a potentially risky surgical biopsy.

http://dx.doi.org/10.3174/ajnr.A5425

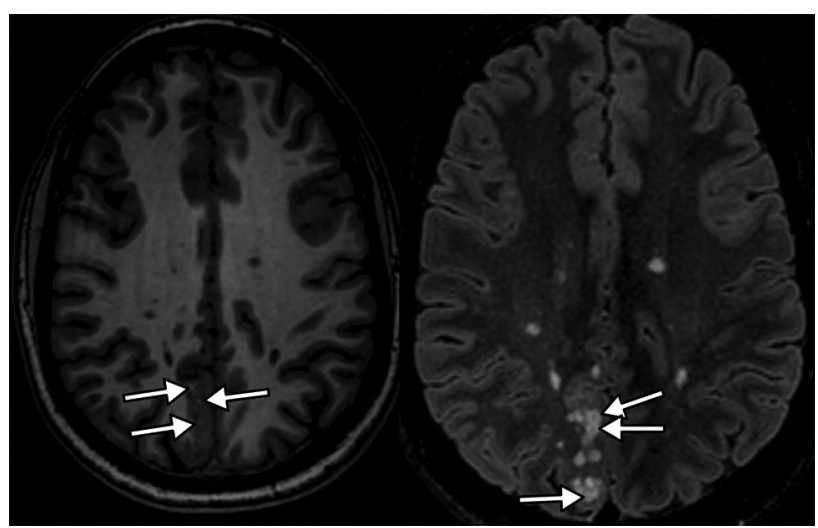

FIG 1. Axial Tl (left) and FLAIR (right) weighted imaging showing a right parietal lesion involving the deep cortical ribbon and the adjacent subcortical white matter distributed into small coalescent nodules, hyperintense on FLAIR, hypointense with punctiform hyperintensities on TIWI, and central hypointensities on FLAIR (arrow), characteristics of MVNT.

We think that this systematic approach best serves patients because this entity is provisionally considered a brain tumor by the World Health Organization and should be best understood using state-of-the-art MR imaging characterization. This management allows clinicians to reassure their patients who are often frightened by the term "tumor" and sometimes request surgical removal. In our experience, which is further echoed in the article, long-term follow-up MR imaging performed $>10$ years after the first discovery of a presumed MVNT shows perfect stability of brain abnormalities with rare or absent clinical symptoms.

We entirely agree with the authors' conclusion suggesting that MVNT is more likely a malformative lesion as opposed to a neoplasm. Clinical and histologic analysis have not yet provided clear evidence for a neoplastic process. Molecular investigations in few cases have so far failed to reveal IDH1/2, BRAF V600E, EGFR, ERBB2, KRAS, BRAF, NRAS, PIK3CA, and AKT1 mutations or obvious DNA copy number abnormalities. A point mutation involving MEK1 (MAP2K1) p. Q56P (c.167A>C) in non-small-cell lung cancers has been found in 1 case.

Thus, we believe that the name of this entity should be changed to remove the term "tumor" and replaced by the term "hamar- 


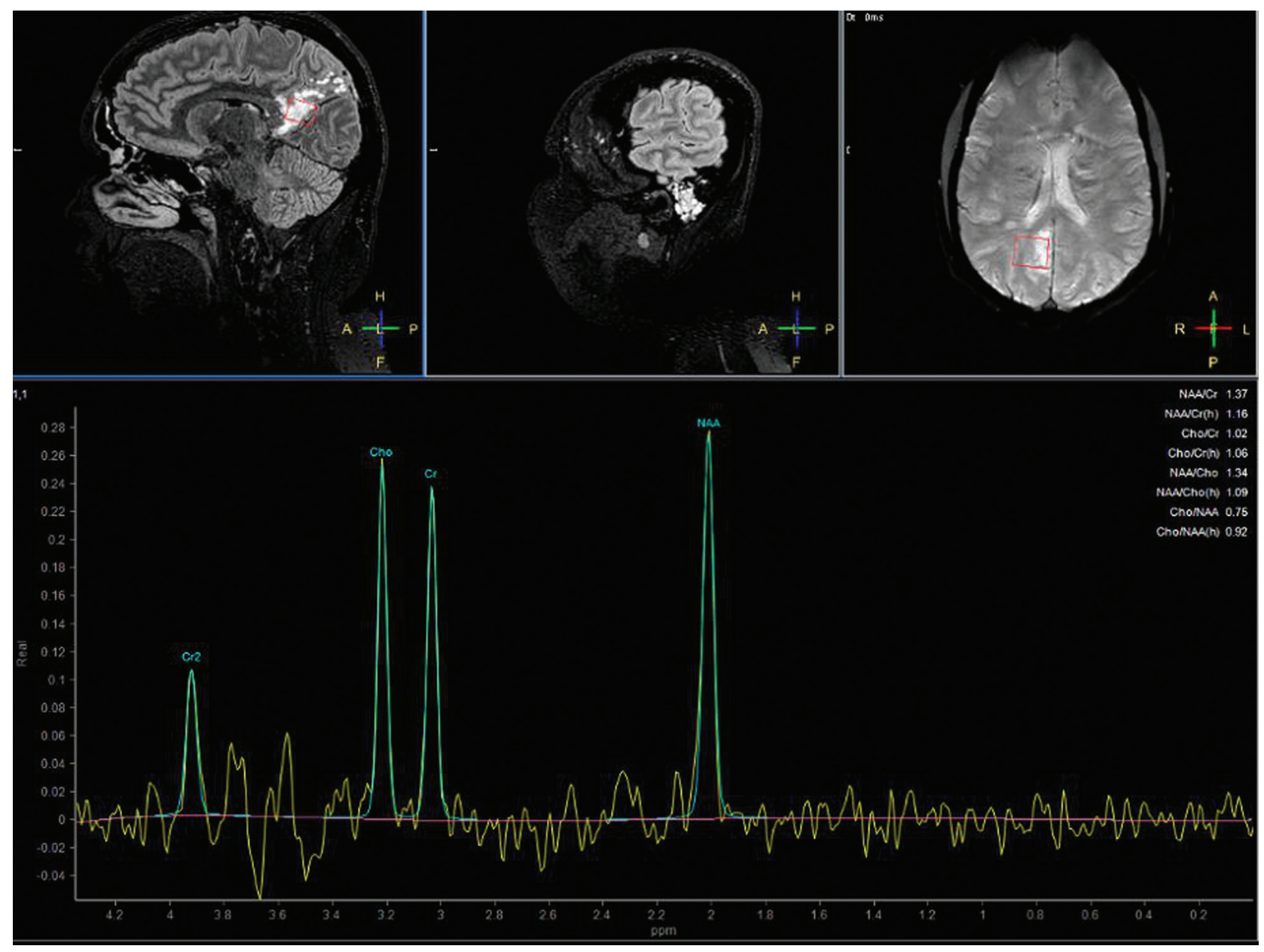

FIG 2. MR spectroscopy shows a mild decrease of $N$-acetylaspartate but no choline or lipids peaks.

toma," "dysplasia," or "malformation." We also believe that larger series are needed to determine at what point the entity will be considered malignant.

Disclosures: Homa A. Biassette-UNRELATED: Grants/Grants Pending: DEVELAGE FP7 grant, * Comments: 2012-2015 “DEVELAGE: Pathways Common to Brain Development and Ageing: Defining Strategies for Preventive Therapy and Diagnostics." Julien Savatovsky_UNRELATED: Grant: Association de la Recherche Sur le Syndrome Immuno-Deficitaire Acquis; Consulting Fee or Honorarium: Association de la Recherche Sur le Syndrome Immuno-Deficitaire Acquis, Madday Pharmaceutical, BristolMyers Squibb, GlaxoSmithKline; Support for Travel to Meetings for the Study or Other Purposes: GE Healthcare, Philips Healthcare, Bayer HealthCare; Expert Testimony: Philips Healthcare, Bayer HealthCare*; Payment for Lectures Including Service on Speakers Bureaus: Philips Healthcare, Association de la Recherche Sur le Syndrome Immuno-Deficitaire Acquis, Biogen.* *Money paid to the institution.

\section{REFERENCES}

1. Nunes RH, Hsu CC, da Rocha AJ, et al. Multinodular and vacuolating neuronal tumor of the cerebrum: a new "leave me alone" lesion with a characteristic imaging pattern. AJNR Am J Neuroradiol 2017;38: 1899-904 CrossRef Medline

2. Fukushima S, Yoshida A, Narita Y, et al. Multinodular and vacuolat- ing neuronal tumor of the cerebrum. Brain Tumor Pathol 2015;32: 131-36 CrossRef Medline

3. Huse JT, Edgar M, Halliday J, et al. Multinodular and vacuolating neuronal tumors of the cerebrum: 10 cases of a distinctive seizureassociated lesion. Brain Pathol 2013;23:515-24 CrossRef Medline

4. Louis DN, Perry A, Reifenberger G, et al. The 2016 World Health Organization Classification of Tumors of the Central Nervous System: a summary. Acta Neuropathol 2016;131:803-20 CrossRef Medline

(1D) A. Lecler Department of Radiology (D) D. Chauvet

Department of Neurosurgery Fondation Ophtalmologique Adolphe de Rothschild

Paris, France

(D).A. Biassette

Department of Pathology Lariboisière Hospital, Paris-Diderot, Paris-Cité-Sorbonne University

Paris, France

(D) J. Savatovsky

Department of Radiology Fondation Ophtalmologique Adolphe de Rothschild Paris, France 